\title{
Large scale related effects on the determination of plant communities and relationships with environmental variables
}

\author{
P. B. Drewa ${ }^{1,2}$ and G. E. Bradfield ${ }^{1,3}$ \\ ${ }^{1}$ Department of Botany, University of British Columbia, 6270 University Blvd., Vancouver, BC, Canada \\ V6T 1Z4.E-mail: garyb@interchange.ubc.ca. \\ 2 Present address: Jornada Experimental Range, USDA-Agricultural Research Service, Box 30003, MSC 3JER, \\ New Mexico State University, Las Cruces, NM, USA 88003.E-mail: pdrewa@nmsu.edu. \\ ${ }^{3}$ Author responsible for correspondence.
}

Keywords: Environmental variance explained, Grain size, Minimum increase of sum of squares cluster analysis, Principal component analysis, Sampling scale, Vegetation classification.

\begin{abstract}
The influence of scale on the discernment of plant community patterns was examined using vegetation-environment data collected from a subalpine wet meadow in south-coastal British Columbia. Species cover data were recorded in $225,0.25 \mathrm{~m}^{2}$ quadrats systematically located at $5 \mathrm{~m}$ intervals in a $40 \mathrm{~m}$ x $120 \mathrm{~m}$ sampling grid. Environmental data consisted of quadrat elevations as well as measured and kriged estimates of five soil variables (carbon content, $\mathrm{pH}$, electrical conductivity, percent sand, and percent clay). Sampling scale was adjusted by aggregating neighbouring quadrats into composite sampling units; analytical scale was altered by varying the intercept level in dendrograms from minimum increase of sum of squares cluster analysis of the vegetation data corresponding to the different sampling scales. The resulting classifications were evaluated for their ability to explain variation in the vegetation data and in the environmental data. The vegetation variation explained by the classifications was highest at the smallest sampling scale indicating that vegetation heterogeneity is fine grained. In contrast, the environmental variation explained was higher for the classifications based on the larger composite sampling units implying a coarser scaling of abiotic conditions within the study area. These results were consistent with the recognition of three main zones along a drainage gradient within the sampling grid upper mixed-forb, middle heath, and lower sedge. There was also evidence that the orientation of rectangular sampling units parallel to the drainage gradient leads to higher levels of explained variation. This study reaffirms the need for careful consideration of alternatives both in field sampling and analytical phases of vegetation research to ensure that description and interpretation of patterns adequately address study objectives and that vegetation-environment relationships are more completely investigated from a hierarchical perspective.
\end{abstract}

Abbreviations: MISSQ-Minimum increase of sum of squares cluster analysis; PCA-Principal component analysis.

Nomenclature: Hitchcock and Cronquist (1973)

\section{Introduction}

Hierarchical classifications of plant community data rarely explore the influence of changing the sampling scale and dendrogram level on the proportion of vegetation and environmental variation explained. Sampling unit size has long been known to affect the form and interpretation of vegetation pattern (Evans 1952, Goodall 1961, Kershaw 1961, Noy-Meir et al. 1970, Greig-Smith 1983). In particular, block size variance analysis (GreigSmith 1952, 1961, Austin 1968) and multiple pattern analysis (Noy-Meir and Anderson 1971) not only demonstrated how varying quadrat size alters the elucidation of vegetation patterns but also affects the interpretation of vegetation-environment relationships. More recently, the manipulation of sampling unit size has become a standard method to examine scale related influences in studies of pattern-process relationships (Reed et al. 1993, Schaefer and Messier 1995, Qi and Wu 1996, Rescia et al. 1997, Fortin 1999).

Classification may provide a basis for invoking process-oriented explanations for the groups generated. In this context, the statement by Diggle (1983) should be heeded: "The nature of the pattern generated by a biological process can be affected by the physical scale on which the process is observed." Similarly, selection of generated 
groups from a cluster analysis influences pattern interpretation and, in turn, affects the clarity with which patternprocess relationships are interpreted.

Selection of an appropriate dendrogram level from hierarchical cluster analysis is a difficult problem for two reasons. First, hierarchical clustering methods provide little guidance in choosing the number of groups in a data set. Second, the effectiveness of procedures used to determine the number of clusters may be a function of inherent qualities of the data (Everitt 1980, Milligan and Cooper 1985). Numerous methods have been developed to select the number of groups in a data set (Marriot 1971, Calinski and Harabasz 1974, Ratliff and Pieper 1981). In particular, Thorndike (1953) and Gower (1975) introduced similar methods to determine the number of clusters where mean within-cluster distance is plotted against the number of data partition groups. Multiple discriminant analysis has been used to test the goodness of classification (Matthews 1979); however, this method is limited by the assumption of equal variance-covariance matrices, and by arbitrary decisions relating to probability levels and the dimensionality of the discriminant space (Podani 1984). Stopping rules have also been developed to determine the number of clusters in a classification (Hogeweg 1976, Hill 1980, Popma et al. 1983). More recently, Pillar (1999) proposed a method that statistically validates the selection of a dendrogram level through simulated resampling of vegetation data via bootstrapping.

Levels in a hierarchy of varying observational scales are a function of observer-chosen criteria (Allen and Starr 1982, O’Neill et al. 1986). We recognize two hierarchies in this study: a hierarchy of sample unit size (termed 'grain' size), and a classification hierarchy related to the sequence of linkages joining the sampling units in a dendrogram. A sampling unit hierarchy is comprised of levels determined by different sizes and shapes of sampling units: fine-scaled observations are a function of small quadrat sizes; coarser-scaled observations may be made using larger quadrats in the field or, as described here, by combining neighbouring quadrats to construct coarserscaled composite sampling units (Gauch 1982). A classification hierarchy refers to the results generated by a hierarchical cluster analysis corresponding to a particular sampling scale, diagrammatically represented as a dendrogram. In addition, plant community patterns can be viewed from different reference points while maintaining the same observational scale (Bradfield and Orlóci 1975, Allen and Starr 1982). For example, this may be accomplished by using a rectangular quadrat and altering its orientation.
In this paper, we present a methodological approach to exploring how vegetation patterns may shift with changes in sampling scale and dendrogram levels. We examine also the consequences of those changes for explaining total variation in species composition and environmental data. A sampling unit hierarchy was constructed by combining adjacent units together from a grid sampling design used to collect information on species distribution and abundance patterns in relation to environmental conditions. A cluster analysis of the vegetation data at each sampling scale yielded different classification hierarchies of the same vegetation for comparison. We address two questions related to vegetation classification: 1) What effect does altering the sampling scale have on the discernment of plant community patterns? and 2) What is the relationship between sampling scale, dendrogram level, and the proportion of variation explained in species composition and environmental factors? These questions were addressed using data collected from a subalpine wet meadow of south-coastal British Columbia.

\section{Methods}

\section{Study area}

The study site is a subalpine wet meadow located at an elevation of ca. $1700 \mathrm{~m}$ above sea level in the Black Tusk recreation area of Garibaldi Provincial Park (Fig. 1). Total mean annual precipitation recorded over a thirty year period (1951-1980) at a nearby weather station (Alta Lake, $648 \mathrm{~m}$ in elevation) was $1415 \mathrm{~mm}$, almost half of which was snow (657 mm; Environment Canada 1980). Average monthly temperatures are mild during June-August $\left(12.5^{\circ} \mathrm{C}-15.3^{\circ} \mathrm{C}\right)$, although snow cover may persist well into the growing season. Freezing temperatures and deep snow are common from October to April $\left(0.6^{\circ} \mathrm{C}\right.$ av-

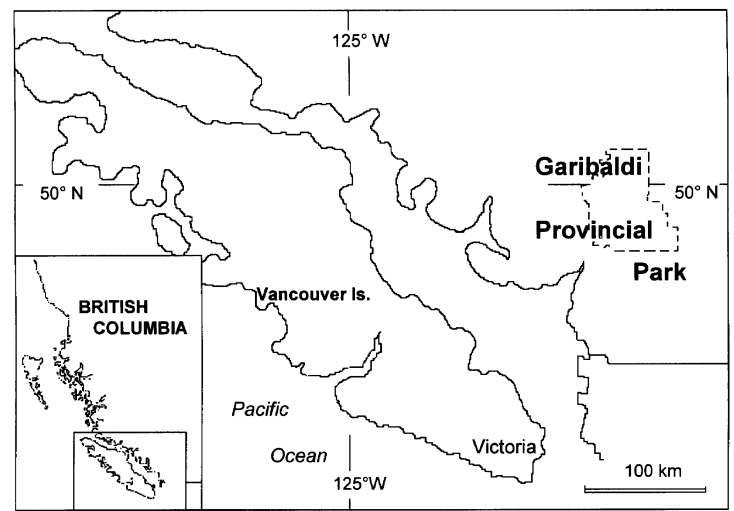

Figure 1. Map showing regional location of the study area in Garibaldi Provincial Park, south-coastal British Columbia. 
erage monthly temperature). The vegetation is similar to that described for other subalpine wet meadow sites in coastal British Columbia (Brink 1959, Brooke et al. 1970, Brett et al. 1998). The lower portion of the site borders on a small lake and is characterized by a virtually monospecific stand of Carex nigricans. At slightly higher elevations with improved drainage, a mixed forb-heath vegetation-type is present with species such as Phyllodoce empetriformis, Cassiope mertensiana, Lupinus latifolius, Luetkia pectinata, Erigeron peregrinus, and Valeriana sitchensis.

\section{Field sampling}

Within the study area, percent coverage of plant species was estimated visually in $225,0.5 \mathrm{~m}$ x $0.5 \mathrm{~m}$ quadrats systematically located at $5 \mathrm{~m}$ intervals in a $40 \mathrm{mx} 120 \mathrm{~m}$ sampling grid. The sampling grid was positioned with the long axis running upslope, along the drainage gradient away from the lake's edge. Quadrat elevations relative to the lowest point in the sampling grid were determined using a standard surveyor's level. A total of sixty-five soil sample units were collected from the centre of every other quadrat throughout the sampling grid. Soil sample units were taken to a depth of ca. $15 \mathrm{~cm}$, air dried at approximately $20^{\circ} \mathrm{C}$ (Jackson 1958, Davidescu and Davidescu 1982), and analyzed for $\mathrm{pH}$, electrical conductivity (Rhoades 1982), carbon content (Leco analyzer), and texture (hydrometer method). These environmental variables were selected because they have been associated with subalpine plant communities throughout the Pacific coastal region of northwestern North America (Brink 1959, Brooke et al. 1970, Kuramoto and Bliss 1970, Douglas and Bliss 1977, Evans and Fonda 1990). Further, they have been shown to be influenced by soil moisture patterns under conditions similar to those in the present study area (Isard 1986, de Molenaar 1987).

\section{Assembly of coarser sampling scales}

Coarser scales of observation were constructed by combining neighbouring quadrats in the field sampling grid and calculating mean percent coverage values of species for larger composite sampling units (Gauch 1982). In this fashion, five aggregation designs of the basic quadrats (termed 'agg' scales), each representing a different scale of observation for the same vegetation, were generated. The agg1 scale consisted of the 225 basic quadrats $(0.5 \mathrm{~m} \times 0.5 \mathrm{~m})$ used in the field sampling grid (i.e., no aggregation). The agg 4 and agg9 scales consisted of nonoverlapping aggregations of the basic quadrats in groups of four and nine, located within areas of $5 \mathrm{~m} \times 5 \mathrm{~m}$ and 10 $\mathrm{m} \times 10 \mathrm{~m}$, respectively. Additionally, two orientations of a rectangular composite sampling unit, combining the quadrats in groups of six within a $5 \mathrm{~m} \times 10 \mathrm{~m}$ area, were constructed: agg6a was assembled by aggregating quadrats in rectangular-shaped groups, oriented across the drainage gradient (i.e., perpendicular to the long axis of the sampling grid); agg6b was assembled in the same way but oriented parallel to the length of the sampling grid. In aggregating the basic quadrats to form coarser sampling scales, no attempt was made to nest the smaller scale sampling units at agg4 and agg6a/b within the larger units at the agg9 scale. Thus, the different sampling scales did not represent a spatial hierarchy in a strict sense. On the other hand, the reassembly of basic quadrats at the coarser sampling scales was considered advantageous for making cross-scale comparisons of the vegetation patterns.

\section{Cross-scale comparison of plant community patterns}

Delineation of plant community patterns within the sampling grid was performed using MISSQ (Ward 1963) with chord distance based on species coverage data as the quantitative measure of dissimilarity among quadrats (Orlóci 1967). MISSQ was selected from among other clustering methods because it produces homogeneous groups with minimum within-group and maximum betweengroup variability. Five MISSQs were performed, one on each of the vegetation data sets arising from the five aggregation designs. Sample sizes available for analysis declined with increasing scale given the aggregations of basic quadrats (for agg1, $\mathrm{n}=225$; for agg $4, \mathrm{n}=48$; for agg6a, $n=36$; for agg6b, $n=32$; for agg9, $n=24$ ).

Evaluations of the total vegetation and environmental variation explained by the MISSQ results were determined using the method outlined by Jongman et al. (1987), as implemented in the forward selection procedure in CANOCO (ter Braak 1990). In this procedure quadrat groups corresponding to a particular dendrogram level were designated by dummy variables ( $0 / 1$ values) indicating group membership of the respective sampling units. The dummy variables were then treated as nominal explanatory variables in a multiple least-squares regression procedure for determining the fraction of total species and environmental variation explained by the respective MISSQ groups. Only the top nine dendrogram levels, producing from two to ten clusters (referred to as levels C2-C10), were evaluated for their effectiveness in accounting for overall variation in the data. Dendrogram levels beyond the ninth were not examined given the increase in pattern detail and limited practicality for field interpretation of the clustering results. Estimates of the fraction of total species variation explained by the MISSQ groups, regardless of sampling scale at which the MISSQs 
were performed, were made with reference to the species composition data at the agg 1 scale. This method avoided the problem of basing the evaluations on different vegetation data sets, thus maintaining consistency in making cross-scale comparisons.

The vegetation classifications at each sampling scale also were assessed for their ability to explain variation in the environmental data. In this case, the problem of missing soil data for alternating quadrats throughout the sampling grid was addressed by applying punctual kriging (Gamma Design Software 1991) to estimate values of the five soil variables ( $\mathrm{pH}$, conductivity, carbon content, percent sand, and percent clay) for the unsampled quadrats. The kriged estimates were determined through application of semivariance and anisotropic best fit model analyses based on measured values in the local neighbourhood. The complete environmental data set used for evaluating the vegetation classifications thus consisted of elevation plus the measured and kriged estimates of five soil variables for the 225 quadrats of the sampling grid.

Sampling grid maps, showing the vegetation-types corresponding to the different combinations of sampling scales and dendrogram levels, were drawn to facilitate visual comparison of the plant community patterns. A corresponding map for the environmental data displayed variation within the sampling grid along the first axis from PCA of the six environmental variables.

\section{Results}

A total of 35 vascular plant species and one, common species of sphagnum moss were recorded within the sampling grid. The most frequently recorded species were Carex nigricans (90\% frequency), C. spectabilis (50\%), Erigeron peregrinus (48\%), Caltha biflora (44\%), Epilobium anagallidifolium (43\%), and Juncus sp. (40\%). Sixteen species occurred in fewer than $10 \%$ of the quadrats. Two species of low shrubs, Cassiope mertensiana (24\%) and Phyllodoce mertensiana (18\%), occurred with intermediate frequency.

For all sampling scales, the variation in species composition explained by the MISSQ results rose with increasing levels of refinement in the dendrograms (i.e., from $\mathrm{C} 2$ to $\mathrm{C} 10$; Fig. 2a). The steepest rise occurred from $\mathrm{C} 2$ to $\mathrm{C} 3$. In general, the variation explained was consistently highest at the agg 1 scale suggesting that vegetation pattern tends to be fine grained. Total vegetation variation explained by the classifications remained low $(<35 \%$ variance explained by ten clusters at the agg 1 scale) indicating the presence of considerable noise in the vegetation data; thus, boundaries between plant communities in the meadow may not be clearly defined.

In contrast to the vegetation results, the coarser sampling scales (agg4-agg9) explained a greater proportion of environmental variation than the agg1 scale implying that environmental heterogeneity is coarse-grained (Fig. 2b). Also, the total environmental variation explained (ca. $75 \%$ by dendrogram level $\mathrm{C} 10$ ) was higher than that for vegetation. Because of the smaller number of environmental variables analyzed (i.e., 6 environmental variables versus 36 plant species) and the relatively consistent changes in environmental conditions along the elevation gradient, these data may have contained less noise. The steep rise in variance explained from two to three groups for most sampling scales suggested the occurrence of three general environmental zones within the sampling grid. The agg6b sampling design yielded the highest levels of environmental variation explained over the range of three to five groups suggesting a concordance between vegetation and environmental pattern in a direction parallel to the main drainage gradient.
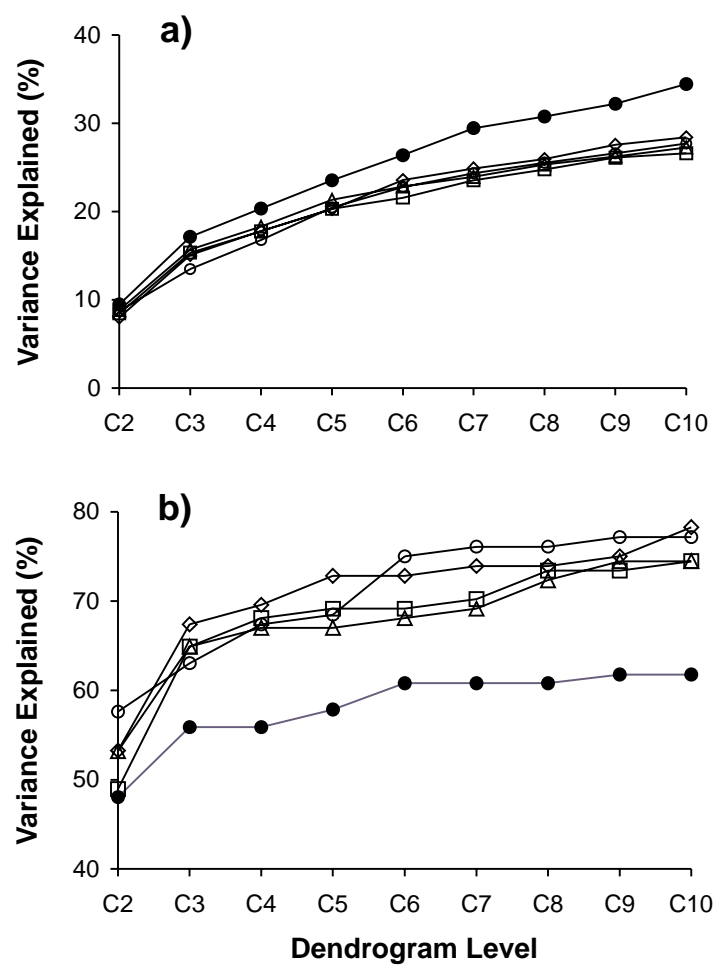

Figure 2. Variation explained in species composition (a) and environmental data (b) by vegetation patterns corresponding to dendrogram levels C2-C10 from MISSQ Symbols denote sampling scales on which the vegetation classifications were based: agg1 (○), agg4 (O), agg6a $(\triangle), \operatorname{agg} 6 \mathrm{~b}(\diamond), \operatorname{agg} 9(\square)$. 

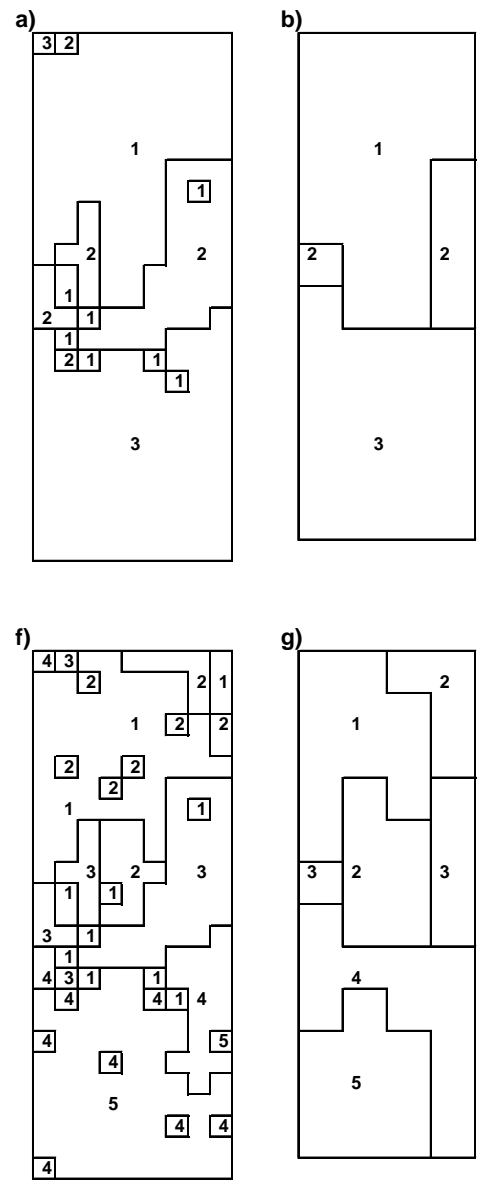
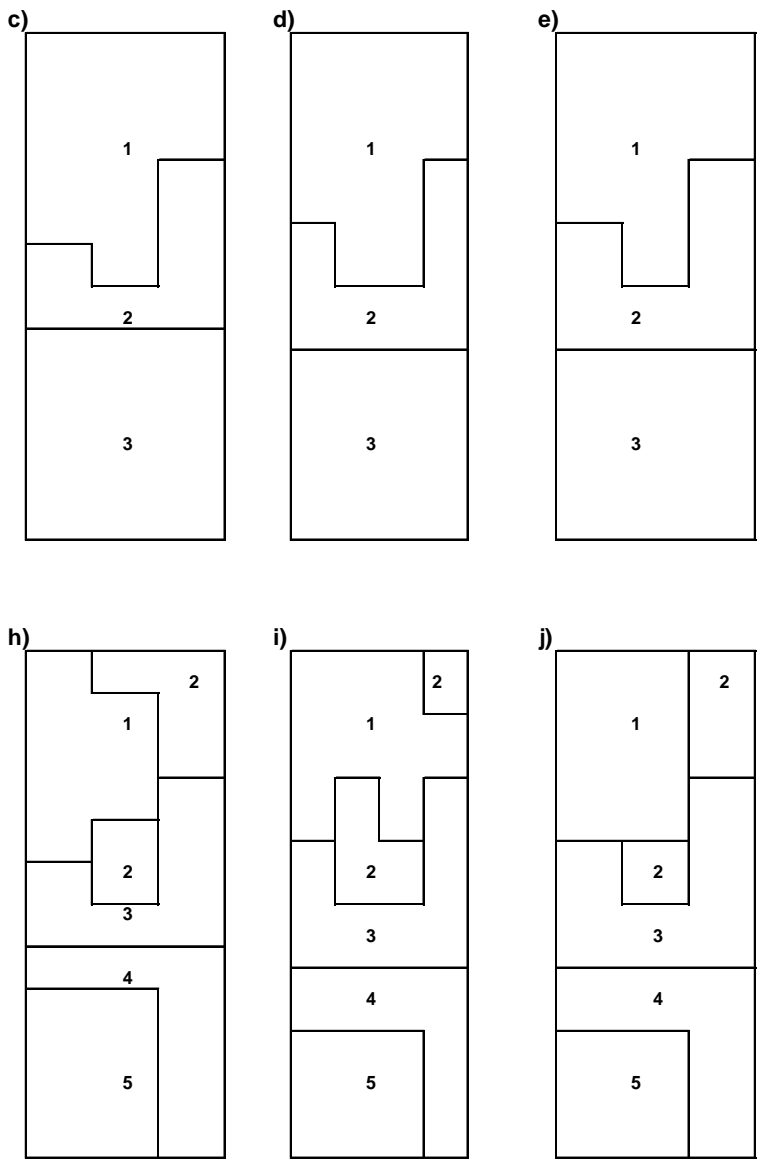

Figure 3. Sampling grid maps showing vegetation patterns corresponding to the three-group (a-e) and five-group (f-h) dendrogram levels from MISSQ. Vegetation patterns are shown for the five sampling scales employed: agg1 (a,f), agg4 (b,g), agg6a (c,h), agg6b (d,I), agg9 (e,j). Dimensions of the sampling grid are $120 \mathrm{~m} \mathrm{x} 40 \mathrm{~m}$. The bottom edge is adjacent to a small subalpine lake.

The sampling grid maps of the MISSQ results indicated that similar vegetation patterns were detected across a range of sampling scales (Fig. 3). Greater pattern detail was evident at the agg1 scale, but the general features were similar to those at the coarser sampling scales. At the three-group level, three vegetation zones were evident along the length of the sampling grid: an upper zone (labeled 1 in Fig. 3a-e) characterized by sedges (Carex nigricans, C. spectabilis) and forbs (Erigeron peregrinus, Lupinus latifolius, Valeriana sitchensis); a middle zone (2) characterized by low shrubs (Cassiope mertensiana, Phyllodoce empetriformis) and herbs (Caltha biflora, Carex nigricans, Erigeron peregrinus, Luetkea pectinata); and a lower zone (3) dominated by a sedge (Carex nigricans), with interspersed forbs (Caltha biflora, Leptarrhena pyrolifolia).

At the five-group level, two sub-groups of the upper zone (labeled 1 and 2 in Fig. 3f-j) and lower zone (4 and 5 ) were recognized. The middle zone (3) was the same as that at the three-group level. The general configuration of the pattern boundaries and the disjunction within the upper zone suggested that processes determining vegetation pattern become more complex with increasing distance from the lake.

A surface map of sampling unit first axis scores from the PCA performed on the environmental data indicated a complex gradient running along the length of the sampling grid (Fig. 4). The first PCA axis explained $60 \%$ of the variance in the environmental data, and was positively correlated, in a direction toward the lake, with increasing $\mathrm{pH}$ (Pearson $r=0.83$ ) and percent clay (0.89), and negatively correlated with elevation (-0.94), electrical conductivity (-0.83), and percent sand (-0.74). The second PCA axis was correlated with percent carbon $(-0.91)$; however, the small eigenvalue for the second axis $(19 \%$ of variance explained) indicated that its usefulness for interpretation was limited. Apart from a general conformity between vegetation and environmental zones along the length of the sampling grid, a precise matching of the environ- 


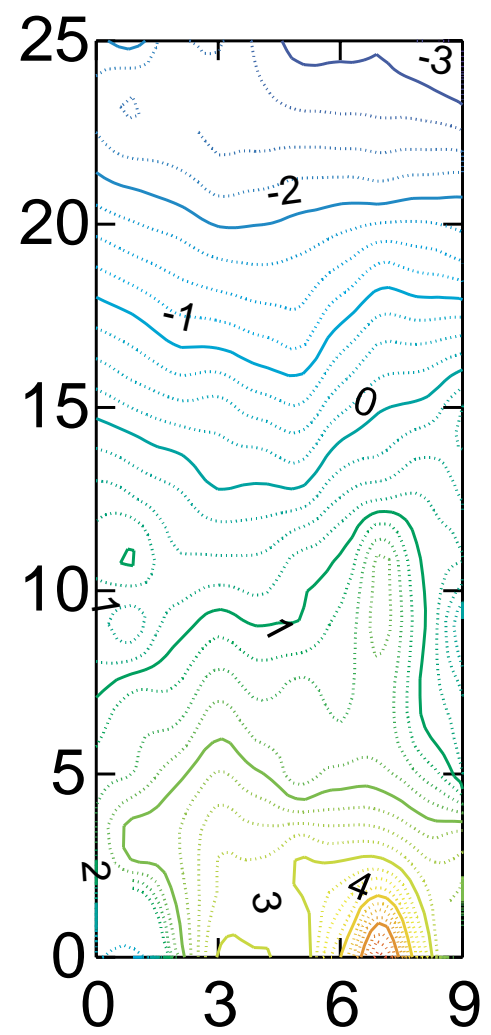

Figure 4. Surface map of quadrat first axis scores from PCA performed on the environmental data within the sampling grid.

mental variation with vegetation pattern boundaries was not apparent (cf. Figs. 3 and 4).

\section{Discussion}

We have shown that changing the size and orientation of sampling units may alter the perception of vegetation pattern and the extent to which vegetation heterogeneity is correlated with environmental conditions. In this respect, our results from a subalpine meadow are similar to other studies where effects of sampling scale on interpretation of vegetation boundaries have been examined. For example, Fortin (1999) showed evidence for shifts in vegetation pattern boundaries (i.e., ecotones) in a northern hardwood forest depending on quadrat size and shape, and nature of data analysed (density, cover, presence/absence). Similarly, Reed et al. (1993) found a higher degree of correlation between vegetation and environmental factors with increasing grain size during sampling. Whereas our study did not examine scale effects related to the extent or total size of the area sampled, it is unlikely that this component of scale would greatly alter the results.
The results of this study suggest there may be merit in aggregating small quadrats to form larger composite units prior to statistical analysis where the objective is pattern detection (sensu Kenkel et al. 1989). Regardless of dendrogram level used to delineate plant communities, a notable effect of sampling scale was the pronounced decline in apparent patchiness of the vegetation between the agg 1 scale and all higher scales (Fig. 3). By aggregating adjacent quadrats, much of the fine-scale patchiness disappeared, and a spatial pattern emerged that remained relatively stable with further increases in sampling scale. Whereas the use of small quadrats (i.e., $0.5 \mathrm{~m} \mathrm{x} 0.5 \mathrm{~m}$ ) facilitated the recording of accurate data on species abundance in the field, the analysis of larger composite sampling units led to a clearer synthesis of the major vegetation patterns within the sampling grid. As noted by Kenkel et al. (1989), specific decisions relating to sampling will depend on study objectives. Nonetheless, we feel that the exploratory approach described here may aid in the recognition of plant communities at coarser scales that were otherwise noisy and more difficult to interpret at finer scales.

Analysis of larger sampling units also revealed that abiotic factors affecting vegetation heterogeneity may be operating at spatial scales considerably larger than the sizes of individual plants. In a related study of vegetation pattern in a New Zealand subalpine meadow, Weir and Wilson (1987) also reported successful detection of mesoscale pattern using small quadrats $\left(0.25 \mathrm{~m}^{2}\right)$. In conjunction with our findings, these results point to a strong identity of subalpine meadow vegetation types at very fine scales. On a cautionary note, the extensive use of kriged values in our analysis of environmental data may have contributed to the higher variance explained at the coarser sampling scales. These kriged estimates, despite being of the same grain size as the observed data (Legendre and Legendre 1998), tend to smooth over the actual variation at fine scales. Nonetheless, the relatively continuous nature of the major environmental gradient along the length of the sampling grid suggests that fine scale variation in abiotic conditions is not pronounced.

The slight increase in environmental variation explained by the vegetation classification at the agg6b sampling scale is in agreement with early claims that rectangular quadrats on sloping terrain should be positioned at right angles to observed vegetation zones (Clapham 1932, Bormann 1953). This conclusion, however, remains speculative owing to the limited treatment of rectangular quadrat orientation in this study. In our study site, vegetation pattern may have been strongly influenced by changes in abiotic conditions along the length of the sam- 
pling grid. Although not measured directly, such conditions are likely to be functions of snow melt and drainage patterns during the growing season. During field sampling, a rectangular quadrat oriented parallel to the environmental gradient is more likely to encompass greater variability in species composition, thereby reducing heterogeneity between sampling units (Kalamkar 1932, Greig-Smith 1983). When the data were combined at coarser scales, the lengthwise orientation of units at agg6b helped to bring the vegetation pattern into alignment with physical processes related to water movement along a pronounced elevation gradient with upslope and downslope areas differing by $6 \mathrm{~m}$. An interesting feature of the environmental patterns is the increase in spatial complexity toward the lower meadow area near the lake (Fig. 4). When compared to the vegetation grid maps in Fig. 3, however, it appears that such complexity in soil physical/chemical conditions may be overridden by other factors affecting plant growth, such as delayed snow melt and higher soil water content at the lower elevations.

The relatively low variation in species composition explained by cluster analysis suggested that plant community boundaries are not sharp in the subalpine meadow study site. In part, this problem arises from the tendency for natural vegetation zones to be quite noisy, with boundaries rarely being clearly defined (Minchin 1987, Fortin 1999). Using the MISSQ results for their ability to explain variation in the environmental data provided a basis for selecting a classification that was consistent with a potential causal mechanism underlying the vegetation pattern (i.e., species responses to abiotic gradients). While the precise location of boundaries cannot be determined with this method, it does provide guidelines for determining the optimum number of vegetation units, irrespective of details of the boundaries of such units. This method, however, is not intended to manipulate scale with the express purpose of trying to maximize the degree to which vegetation patterns and environmental variables are correlated. Rather, it should be viewed as a heuristic process for gaining further insight into potential determinants of vegetation pattern which may, in turn, lead to more focused hypotheses about the causes of variation.

A multi-scaled approach such as described here offers the potential for different perspectives to be gained on the underlying processes that determine plant community structure. From a management viewpoint, this could lead to increased options for decision making. For example, in the subalpine meadow, if the maintenance of broad scale vegetation patterns were of prime concern, then interest should center on the three general zones (lower, middle, and upper) represented in the sampling grid. Alterna- tively, if a finer scale of resolution addressing particular features of vegetation heterogeneity is required, then a higher level of resolution in the dendrogram corresponding to the finest sampling scale may provide a more suitable template. Consideration of the scales over which physical processes influence plant communities provides a basis for improved understanding of complex ecosystems.

Acknowledgements: This research was partially supported by a grant from the Natural Sciences and Engineering Research Council of Canada to G.E.B., and The Vladimir J. Krajina Scholarship in Plant Ecology to P.B.D. We thank the British Columbia Ministry of Parks for granting permission to work in Garibaldi Provincial Park. Dr. L.M. Lavkulich and Mr. B.W. von Spindler, Department of Soil Science, University of British Columbia, provided advice and facilities for the laboratory analysis of soil sample units. We are especially grateful to Dr. Wei Zhang for assistance with data analysis. Final revisions to the manuscript were guided by comments from Dr. János Podani and three anonymous reviewers.

\section{References}

Allen, T.F.H. and T.B. Starr. 1982. Hierarchy: Perspectives for Ecological Complexity. University of Chicago Press, Chicago.

Austin, M. P. 1968. Pattern in a Zerna erecta dominated community. J. Ecol. 56:197-218.

Bormann, F.H. 1953. The statistical efficiency of sample plot size and shape in forest ecology. J. Ecol. 34:474-487.

Bradfield, G.E. and L. Orlóci. 1975. Classification of vegetation from an open beach environment in south western Ontario: cluster analysis followed by a generalized distance assignment. Can. J. Bot. 53:495-502.

Brett, R.B., K. Klinka and H. Qian. 1998. Classification of high-elevation, non-forested plant communities in coastal British Columbia. Forest Sciences Department, Univ. British Columbia.

Brink, V.C. 1959. A directional change in the subalpine forest-heath ecotone in Garibaldi Park, British Columbia. Ecology 40:10-16.

Brooke, R.C., E.B. Peterson and V.J. Krajina. 1970. The subalpine mountain hemlock zone. Ecology of Western North America 2:147-349.

Calinski, T. and J. Harabasz. 1974. A dendrite method of cluster analysis. Communications in Statistics 3:1-27.

Clapham, A.R. 1932. The form of the observational unit in quantitative ecology. J. Ecol. 20:192-197.

Davidescu, D. and V. Davidescu. 1982. Evaluation of Fertility by Plant and Soil Analysis. Abacus Press, Kent.

de Molenaar, J.G. 1987. An ecohydrological approach to floral and vegetational patterns in arctic landscape ecology. Arctic and Alpine Research 19:414-424.

Diggle, P.J. 1983. Statistical Analysis of Spatial Point Patterns. Academic Press, London.

Douglas, G.W. and L.C. Bliss. 1977. Alpine and high subalpine plant communities of the north Cascades Range, Washington and British Columbia. Ecol. Monogr. 47:113-150.

Environment Canada. 1980. Temperature and Precipitation, 19511980, British Columbia. Atmospheric Environment Service. Victoria, B.C.

Evans, F.C. 1952. The influence of size of quadrat on the distributional patterns of plant populations. Contributions from the 
Laboratory of Vertebrate Biology of the University of Michigan 54:1-15.

Evans, R.D. and R.W. Fonda. 1990. The influence of snow on subalpine meadow community pattern, north Cascades, Washington. Can. J. Bot. 68:212-220

Everitt, B. 1980. Cluster Analysis, 2nd ed. Halsted Press, New York.

Fortin, M.-J. 1999. Effects of quadrat size and data measurement on the detection of boundaries. J. Veg. Sci. 10:43-50

Gamma Design Software. 1991. GS - Geostatistics for the agronomic and biological sciences (version 1.1). Plainwell, MI

Gauch, H.G. 1982. Multivariate Analysis in Community Ecology. Cambridge University Press, New York.

Goodall, D.W. 1961. Objective methods for the classification of vegetation. IV. Pattern and minimal area. Australian Journal of Botany 9:162-196

Gower, J.C. 1975. Goodness-of-fit criteria for classification and other patterned structures. In: G.S. Estabrook (ed), Proceedings of the 8th International Conference on Numerical Taxonomy. W.H. Freeman and Company, San Francisco, pp. 38-62.

Greig-Smith, P. 1952. The use of random and contiguous quadrats in the study of the structure of plant communities. Ann. Bot. Lond 16:293-316.

Greig-Smith, P. 1961. Data on pattern within plant communities. I. The analysis of pattern. J. Ecol. 49:695-702.

Greig-Smith, P. 1983. Quantitative Plant Ecology. 3rd ed. University of California Press, Berkeley and Los Angeles.

Hill, R.S. 1980. A stopping rule for partitioning dendrograms. Bot. Gaz. 141:321-324

Hitchcock, C.L. and A. Cronquist. 1973. Flora of the Pacific Northwest. University of Washington Press, Seattle.

Hogeweg, P. 1976. Iterative character weighting in numerical taxonomy. Computers in Biology and Medicine 6:199-211.

Isard, S.A. 1986. Factors influencing soil moisture and plant community distribution on Niwot Ridge, Front Range, Colorado, U.S.A. Arctic and Alpine Research 18:83-96

Jackson, M.L. 1958. Soil Chemical Analysis. Prentice Hall Inc. Englewood Cliffs, NJ.

Jongman, R.H., C.J.F. ter Braak and O.F.R. van Tongeren. 1987. Data Analysis in Community and Landscape Ecology. Pudoc, Wageningen.

Kalamkar, R.J. 1932. Experimental error and the field plot technique with potatoes. Journal of Agricultural Science 22:373-383.

Kenkel, N.C., P. Juhász-Nagy, and J. Podani. 1989. On sampling procedures in population and community ecology. Vegetatio 83:195-207.

Kershaw, K.A. 1961. Association and co-variance analysis of plant communities. J. Ecol. 49:643-654

Kuramoto, R.T. and L.C. Bliss. 1970. Ecology of subalpine meadows in the Olympic Mountains, Washington. Ecol. Monogr. 40:317347.

Legendre, P. and L. Legendre. 1998. Numerical Ecology, Second English Edition. Elsevier, New York.

Marriot, F.H.C. 1971. Practical problems in a method of cluster analysis. Biometrics 27:501-514.

Matthews, J.A. 1979. A study of the variability of some successional and climax plant assemblage-types using multiple discriminant analysis. J. Ecol. 66:157-173.
Milligan, G.W. and M.C. Cooper. 1985. An examination of procedures for determining the number of clusters in a data set. Psychometrika 50:159-179.

Minchin, P.R. 1987. Simulation of multidimensional community patterns: towards a comprehensive model. Vegetatio 71:145-156.

Noy-Meir, I. and D.J. Anderson. 1971. Multiple pattern analysis, or multiscale ordination: towards a vegetation hologram? In: G.P. Patil, E.C. Pielou and W.E. Waters (eds), Statistical Ecology Volume 3: Many Species Populations, Ecosystems, and Systems Analysis. The Pennsylvania State University Press, University Park, London, pp. 207-231.

Noy-Meir, I., N.H. Tadmor and G. Orshan. 1970. Multivariate analysis of desert vegetation. I. Association analysis at various quadrat sizes. Israel Journal of Botany 19:561-591.

O’Neill, R.V., D.L. DeAngelis, J.B. Waide and T.F.H. Allen. 1986 A Hierarchical Concept of Ecosystems. Princeton University Press, Princeton, NJ.

Orlóci, L. 1967. An agglomerative method for classification of plant communities. J. Ecol. 55:193-205.

Pillar, V.D. 1999. How sharp are classifications? Ecology 80:25082516.

Podani, J. 1984. Spatial processes in the analysis of vegetation: theory and review. Acta Bot. Hung. 30:75-118.

Popma, J., L. Mucina, O. van Tongeren and E. van der Maarel. 1983. On the determination of optimal levels in phytosociological classification. Vegetatio 52:65-75.

Qi, Y. and J. Wu. 1996. Effects of changing spatial resolution on the results of landscape pattern analysis using spatial autocorrelation indices. Landscape Ecol. 11:39-49.

Ratliff, D. and R.D. Pieper. 1981. Deciding final clusters: an approach using intra- and inter-cluster distances. Vegetatio 48:8386

Reed, R.A., R.K. Peet, M.W. Palmer and P.S. White. 1993. Scale dependence of vegetation-environment correlations: a case study of a North Carolina piedmont woodland. J. Veg. Sci. 4:329-340.

Rescia, A.J., M.F. Schmitz, P. Martin de Agar, C.L. de Pablo andF.D Pineda. 1997. A fragmented landscape in northern Spain analyzed at different spatial scales: implications for management. $J$. Veg. Sci. 8:343-352.

Rhoades, J.D. 1982. Soluble salts. In: A.L. Page, R.H. Miller and D.R. Keeney (eds), Methods of Soil Analysis, Part 2. Chemical and Microbiological Properties. American Society of Agronomy-Soil Science Society of America, Madison, WI, pp. 167179.

Schaefer, J.A. and F. Messier. 1995. Scale-dependent correlations of arctic vegetation and snow cover. Arctic and Alpine Research 27:38-43.

ter Braak, C.J.F. 1990. Update notes: CANOCO version 3.10. TNO Institute of Applied Computer Science, Wageningen.

Thorndike, R.L. 1953. Who belongs in a family? Psychometrika 18:267-276.

Ward, J.H. 1963. Hierarchical grouping to optimize an objective function. American Statistical Association Journal 58:236-244.

Weir, D.A., and Wilson, J.B. 1987. Micro-pattern in an area of New Zealand alpine vegetation. Vegetatio 73:81-88. 